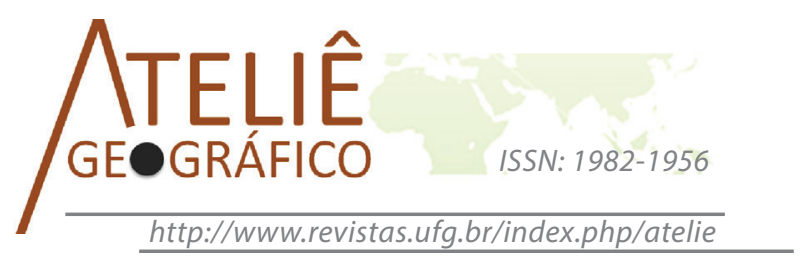

\title{
Testemunho da natureza social: o homem, espaço e tempo amazônico nas representações geográficas do amazonófilo Leandro Tocantins
}

\author{
Testimony of social nature: Man, space and time in the \\ Amazon geographic representations of amazonófilo \\ Leandro Tocantins
}

\section{Testimonio de la naturaleza social: El hombre, el espacio y el tiempo en las representaciones geográficas amazónicas del amazonófilo Leandro Tocantins}

\author{
Márcio Silveira Nascimento \\ Universidade Federal de Roraima \\ marciosn.geo@gmail.com
}

Jaqueline do Espírito Santo Soares dos Santos

Universidade Federal do Amazonas

jackey_santos@yahoo.com.br

\begin{abstract}
Resumo
Este artigo objetiva a análise do espaço amazônico por meio das representações geográficas contidas na obra Amazônia: Natureza, Homem e Tempo, a qual apresenta a história da região em dois tempos: o primeiro num período de expedições em nossos rios, descrito nas obras de cronistas europeus nos séculos XVI e XVII. E num segundo tempo onde ressalta a economia regional baseada nos produtos da floresta. Elucida-se como se deu a descoberta do principal vetor de riqueza daquela época, a borracha, seu uso pelos indígenas e sua consagração na economia mundial. No entanto, a borracha teve seu declínio e levou consigo toda a riqueza, deixando apenas a paisagem bucólica. Também, destacamos a ocupação populacional, mostrando personagens fundamentais na formação social amazônica. Descreve-se ainda um terceiro tempo amazônico que mostra uma nova perspectiva para a região, enaltecendo a relação homem e natureza pautada no viés ecológico que ganhou força com os movimentos sociais e ambientalistas, uma nova visão acerca do espaço da floresta, divergindo das ambições ou da lógica da economia mundial.

Palavras-chave: espaço amazônico, representações geográficas, formação social, borracha.
\end{abstract}




\begin{abstract}
This article aims to analyze the Amazon region through geographic representations contained in the Amazon work: Nature, Man and Time, which presents the history of the area in two stages: the first a period of expeditions in our rivers, described in the works of chroniclers Europeans in the sixteenth and seventeenth centuries. And a second time it emphasizes the regional economy based on forest products. it elucidates how was the discovery of the main vector of wealth that time, rubber, its use by indigenous people and their consecration in the world economy. However, the rubber had its decline and took all the wealth, leaving only the bucolic landscape. Also, we highlight the population occupation, showing key characters in the Amazon social formation. also describes a third Amazonian time showing a new perspective for the region, highlighting the relationship between man and nature guided the ecological bias that gained momentum with social movements and environmentalists, a new vision of the forest space, diverging ambitions or the logic of the world economy.
\end{abstract}

Keywords: amazon region, geographic representations, social formation, rubber.

\begin{abstract}
Resumen
Este artículo objetiva el análisis del espacio amazónico por medio de representaciones geográficas contenidas en la obra de Amazonia: La Naturaleza, El Hombre y El Tiempo, a cual presenta la historia de la región en dos etapas: la primera en un período de expediciones en nuestros ríos, que se describen en las obras de cronistas europeos en los siglos XVI y XVII. Y la segunda etapa donde rebota la economía regional basada en los productos forestales. Aclara como se dio la descubierta del principal vector de la riqueza en aquella época, el caucho, y su uso por los indígenas y su consagración en la economía mundial. Sin embargo, el caucho tuvo su declive y se llevó toda la riqueza, dejando sólo el paisaje bucólico. También, destacamos la población ocupacional, que muestra personajes clave en la formación social del Amazonas. Aún se describe una tercera etapa amazónica que muestra una nueva perspectiva para la región, destacando la relación entre el hombre y la naturaleza enumerada en el oblicuo ecológico que ganó fuerza con los movimientos sociales y ambientalistas, una nueva visión acerca del espacio forestal, divergiendo de las ambiciones o de la lógica de la economía mundial.
\end{abstract}

Palabras clave: región amazónica, representaciones geográficas, la formación social, caucho.

\title{
Introdução
}

Para compreender o que é Amazônia e suas representações no espaço local, nacional e mundial é fundamental periodizar os acontecimentos históricos que ocorreram nessa região. No processo de ocupação, desenvolvimento populacional e atividade econômica da Amazônia brasileira podem-se considerar dois grandes períodos proposto pelo amazonófilo ${ }^{1}$ Leandro Tocantins em sua obra Amazônia: Natureza, Homem e Tempo que aponta a Borracha como marco divisor dos períodos. Mas, outros autores, como Roberto Lobato Corrêa e Bertha Becker de acordo com suas perspectivas também propuseram classificações periódicas para a Amazônia.

1. Todas as obras de Leandro Tocantins têm como foco a Amazônia, notável historiador e, de fato, ele foi um dedicado pesquisador da vida e da história da Amazônia, daí por que Gilberto Freire dizia, carinhosamente, que ele era um "amazonófilo". 
De acordo com Becker (2007) o processo histórico de ocupação regional ocorreu em três períodos: o primeiro é a Formação Territorial (1616-1930) dividido em Apropriação do Território (1616-1777), Delineamento da Amazônia (1850-1899) e Definição dos Limites (1899-1930), o segundo é o Planejamento Regional (19301985) dividido em Início do Planejamento (1930-1966) e A Produção do Espaço Estatal (1966-1985) e a terceira é a Incógnita do Heartland (1985-...) dividido em A Fronteira Socioambiental (1985-1996) e Tendências Atuais (1996-...). Esta classificação do espaço amazônico define as ações desenvolvidas com enfoque social e a ambiental.

Ao pensar no processo de ocupação da região Amazônica tem-se que Corrêa (2006) denomina de períodos curtos e longos, mas para definir a duração de um período deve-se levar em conta a importância dos fatos históricos ocorridos no tempo.

Para Corrêa (2006) a rede urbana amazônica inicia-se na primeira metade do século XVII com a implantação do primeiro núcleo urbano tendo inúmeras modificações que participam da periodização, definindo os "tempos" históricos que estão inseridos na totalidade social. Esta é uma combinação de fatos econômicos, políticos e ideológicos que possuem seu próprio tempo (temporalidade).

A periodização espacial é a reconstrução do tempo espacial. Por exemplo, quando se coloca em evidência um fato e contextualiza-se a história em volta dele, ou seja, está organizando o espaço em favor desse fato, é uma reconstrução.

A relação entre periodização e a escala espacial está nos diferentes segmentos. A incorporação de vários momentos históricos denomina-se de segmentos "velhos" e "novos" que se manifesta de forma distinta em cada lugar de maneira mais rápida ou mais lenta.

O estudo da rede urbana analisa elementos importantes na formação da periodização, como Corrêa (2006) aponta os seguintes elementos: a) a gênese dos núcleos urbanos; b) as funções que desempenham; c) a dependência a determinados produtos; d) o sítio urbano; e) a paisagem urbana; f) a ampliação do número de centros da rede; g) o padrão espacial da rede; h) o papel dos diferentes agentes sociais no processo produtivos; e i) as articulações com os espaços exteriores à rede em questão. Estes estão relacionados entre si, de forma livre e recebendo influência da sociedade que os formam.

Mas a principal questão é a existência da rede urbana na Amazônia, visto a grande extensão e a disposição das cidades. Segundo Mendes (1974) apud Corrêa (2006) “(...) na Amazônia a rede urbana não é equilibrada e ainda que a própria expressão rede urbana careça de significado, pois as cidades não são funcionalmente complementares entre si". No entanto para a função de rede de urbana é necessário ter algum tipo de articulação entre os pontos o que ocorre na Amazônia.

Baseado nisso, concorda-se com Corrêa (2006) quando ele sugere as seguintes condições para se ter uma rede urbana:

- Haver uma economia de mercado com uma produção que é negociada por outra não produzida no local ou regionalmente; 
- Verificar a existência de pontos fixos no território onde os negócios acima referidos são realizados, ainda que com certa periodicidade e não de modo contínuo;

- Referente à existência de um mínimo de articulação entre os núcleos anteriormente referidos, articulação que se verifica no âmbito da circulação, etapa necessária para que as produções exportadoras e importadoras se realizem plenamente, atingindo os mercados consumidores.

Assim, compõem-se uma rede urbana amazônica organizada de maneira peculiar, respeitando as características do lugar onde existem vários padrões de rede urbana e características distintas.

Para Corrêa (2006) a periodização da Amazônia possui os seguintes períodos:

- Um período inicial de implantação da cidade de Belém e o início da conquista do território;

- Um segundo período caracterizado pela expansão dos fortes e a criação de aldeias missionárias, embriões das futuras cidades, (estende-se da metade do século XVII à metade do século XVIII);

- Um terceiro e curto período, marcado por um relativamente importante desenvolvimento da vida econômica e urbana sob a égide da Companhia Geral do Grão-Pará e Maranhão, (estende-se da metade do século XVIII ao final dos anos 70 do mesmo século);

- Um quarto período relativamente longo, que se estende do final do século XVIII à metade do século XIX e que é caracterizado por uma estagnação econômica e urbana;

- O período do boom da borracha, marcada pela expansão e riqueza urbanas, estende-se da metade do século XIX ao final da Primeira Guerra Mundial;

- Um período de estagnação, após a crise da borracha, que se estende, aproximadamente, de 1920 a 1960; e

- Um período atual, iniciado na década de 1960 e que ainda perdura, caracterizado por um intenso processo de mudança econômica e urbana.

Esta periodização é uma tentativa de colocar em evidência o processo de elaboração da rede urbana amazônica. Cada período da história reflete o pensamento sobre a Amazônia, como o primeiro busca a defesa do território com a criação do Forte do Presépio em Belém (1616). O segundo período surgiu com o comércio das especiarias apoiado pelos fortes, aldeias missionárias e na mão-de-obra indígena que estavam no movimento de expansão territorial e ocupação. Importante frisar que as aldeias constituíam os primeiros embriões das cidades.

O terceiro período é considerado "curto" com duração de mais ou menos setenta anos, o então pequeno núcleo embrionário começa a se desenvolver na rede urbana. Com as atividades produtivas desempenhadas pela Companhia Geral do Grão-Pará e 
Maranhão é afetada a rede urbana, as decisões da mudança da capital de São Luis para Belém, doação de sesmarias a colonos e soldados, introdução de escravos africanos, criação e reativação de fortes e criação da Capitania do São José do Rio Negro.

O quarto período reflete a estagnação da vida urbana com a derrocada da Companhia Geral do Grão-Pará e Maranhão no mercado mundial de produtos tropicais. A Amazônia reage com a expansão extrativista da borracha, o quinto período. Assim, a rede urbana ganha novas dimensões, tanto em Belém como em Manaus. O boom da borracha revigora e cria núcleos urbanos e torna a relação intensa entre eles, devido aos produtos (circulação e concentração de atividades).

O sexto período reflete a mais uma estagnação, com a concorrência da borracha da Ásia ocorre a diminuição da produção e da migração na região. Uma característica marcante está nos núcleos que estão cada vez mais independentes da cidade. Desse modo, a crise da borracha afeta principalmente Belém e Manaus. A produção agrícola voltou a crescer e produtos como a juta e a castanha mantêm a economia da região.

E por último, o sétimo período ligado às atividades industriais e projetos de investimentos, como a Zona Franca de Manaus que tem o objetivo de integração nacional e ocupar os "vazios demográficos" na Amazônia. Na rede urbana, surgem mais cidades de maneira mais rápida (ocupações espontâneas) próximas às cidades de Manaus e Belém.

O significado de rede urbana se modifica com a inserção de novos elementos. Com o capital, a indústria e novas atividades surgem os novos núcleos que redefinem as relações sociais. Pensar a rede urbana amazônica é considerar a questão espaço e tempo dos fenômenos sociais. Para Gomes "a análise geográfica liga os fenômenos e os objetos a uma localização formando uma ordem espacial. A Geografia ocupa o espaço produzido pelos fenômenos e objetos que estão localizados em pontos formando uma rede de relacionamento" (2008, p.192). Dessa forma, é observar o modo desigual de como está estabelecida as articulações em cada período dos elementos da rede urbana.

As representações geográficas sobre a Amazônia ganham significados que auxiliam na compreensão da dinâmica e dos processos que ocorrem na região. Retirando a imagem mistificada pela sociedade perante a Amazônia, onde Gomes (2008) explica como se cria e se aumenta um mito por meio da imagem com características distintas de acordo com a sociedade que analisa o mito. Sendo assim, as diferentes visões sobre o mito devem estar entre quem pertence ou não a aquela realidade para classificar o mito positivamente ou negativamente. Portanto, a representação da obra de Leandro Tocantins é válida no sentido de uma visão literária de um filho da terra.

$\mathrm{O}$ autor ressalta os poucos estudos voltados para a Ecologia à época de lançamento do livro Amazônia: Natureza, Homem e Tempo. E o pioneirismo de Gilberto Freyre em Ecologia aplicada a espaços-tempos sociais que contribui com outras teses, como a Lei da "sócio-ecologia" que retrata a adaptação do homem ao meio fisico.

Desde sua primeira obra, O Rio Comanda a Vida (1952) o autor já destacava o papel da Ecologia na Amazônia, onde é definida como "ciência de nossa morada" que está presente em todos seus escritos, em especial, na Amazônia - Natureza, Homem e Tempo 
mostrando uma das primeiras interpretações da Amazônia e suas bases ecológicas. Essa que é a teia da relação homem e natureza (par perfeito) transfundindo-se em tempo: tempo-histórico, tempo-social, tempo-sócio-ecológico e não apenas tempo-vida. A noção de tempo é fundamental na Ecologia, pois o tempo é uma dimensão da vida e em determinado espaço de tempo ocorrem mudanças profundas na natureza.

Mas a relação Homem-Natureza já tinha sido tratada por outros autores como: Bates, Spix e Martius, Wallace, Adolph Ducke, Torquato Tapajós que contribuíram para o desenvolvimento científico da Ecologia. Assim, destaca-se o naturalista suíço Hans Blustschli, um dos primeiros a escrever sobre a relação Homem-Natureza na Amazônia com a obra "A Amazônia como organismo orgânico" indica compreender o todo, reconhecer sua própria alma, que para Leandro Tocantins preferiu chamar de Amazonotropicologia (1968) que ganhou simpatia de Gilberto Freyre e Arthur Reis. A Amazonotropicologia está aberta às novidades e a todos os campos do conhecimento com a busca da harmonia entre o homem e o meio.

No entanto os estudos voltados para a Ecologia ganham força apenas nos anos setenta, a preocupação com os recursos naturais e olhar para a proteção da Amazônia. A relação com a natureza é sentimental tendo o apoio da Ecologia. Mas a relação HomemNatureza tem essência filosófica e até mesmo teológica. Existem fatos que mostram a harmonia do homem e da natureza exposta por São Francisco de Assis em uma ecologia religiosa.

Assim, a natureza na década de 70 ganha ares divinos, a Ecologia como ciência sagrada. A Amazônia como principal elemento de defesa da natureza pede compreensão, enquanto há tempo. Não podemos esquecer que o homem terá o mesmo destino da natureza, se ela está ameaçada ele também estará. A aproximação da ciência e da técnica acelerou o processo de degradação do meio, sendo importante o homem se voltar para sua essência humana. Quanto à obra Amazônia: Natureza, Homem e Tempo apareceu, ela pretendia alerta o que poderia acontecer com a Amazônia no futuro, não com ações de fim do mundo, e sim, preservando e cuidado da natureza.

\section{A Amazônia e seus tempos: das expedições ao ciclo da borracha}

A obra do Leandro Tocantins é essencial para a compreensão da Amazônia. Ela tem como objetivo central retratar as atividades econômicas realizadas por sua população com um olhar mais ecológico, muita vezes utilizada pelo poder público como forma de mascarar a realidade da Amazônia de ontem e de hoje, um começo de substanciais transformações sociais e econômicas.

A obra está dividida em dois tempos: o primeiro tempo e segundo tempo e outros tempos. O primeiro tempo estar dividido em: O Espaço físico-social; Natureza, sociedade e economia; Crônica das gentes, das plantas, dos animais e Colonização, produção, comércio. E que nesse artigo, esses assuntos aparecem citados respectivamente dispostos pelos tópicos: A construção do espaço da Amazônia; A ocupação e formação populacional da Amazônia; A economia na Amazônia e A formação da paisagem amazônica: seus personagens e produtos. Já o segundo tempo e outros tempos estar dividido em: Revelação 
e consagração da borracha; Seringa, seringal e seringueiro; A civilização da borracha e A outra Amazônia. Onde, no artigo os temas abordados respectivamente terão os tópicos: Borracha e o mundo amazônico; Simbiose: trinômio ecológico; Borracha: qual foi seu papel na Amazônia? E o declínio da Borracha e o cenário na Amazônia.

\section{A construção do espaço da Amazônia}

A Ecologia (ciência da nossa grande casa: a Natureza) foi batizada por Ernest Haeckel em 1866 que a reconhece como o estudo das relações com o meio, tendo uma face biológica para Haeckel que se traduz numa competição e luta entre os indivíduos. Lembrando a teia da vida de Darwin com relações complexas entre animais e plantas pela existência (LAGO et al., 1989).

Para compreender o mundo amazônico, sob o ponto de vista da distribuição no espaço físico de seres, grupos e instituições humanas é necessário salientar as relações da teia (entrelaçamento - J. Arthur Thompson) e da adaptação e equilíbrio da relação (sociólogo indiano Mukerjee citado por Freyre).

O homem da Amazônia possui relações com a natureza que formam o processo de desenvolvimento das formas espaciais dos grupos humanos com alusão ao espaço físico e a sua subsistência. A ocupação humana do espaço não deve ser somente físicista ou naturalista, e também considerar os valores (condicionantes de vida e de economia, rios, solo, animais minerais) onde os grupos retiram da natureza fontes de subsistência e de utilidade prática no meio social (FREYRE, 1973).

A ocupação do homem na "planície" Amazônia se deu de forma ecológica com fatores de geográficos, naturais, políticos, sociais, econômicos, culturais entre outros. A Amazônia pelo seu vasto espaço físico ficou impossibilitada de regir a interação do homem com natureza (expressão cultural - regional) nos primeiros séculos de colonização. Um dos elementos que se destaca são seus rios que foram descritos pelos padres Antonio Vieira e João Daniel. Ainda, Samuel Bechimol com uma visão de um imigrante na Amazônia. Outro é o poder que a floresta tem sob as várias formas de vida. E a paisagem (água e floresta) formada cheia de dificuldades para humanizar.

Sobre a representação da imagem da Amazônia, mostra-se um olhar de homem imaginativo, como citam Spix \&Martius (1981) ao se deparar no Rio Tocantins com uma colméia vegetal de palmeiras buriti, sua abordagem carregada de nostalgia transmite um verdadeiro espetáculo da natureza. O espaço físico-social contempla a história do lugar e as relações sociais e econômicas dos colonos e nativos, como as formas de organizar e interagir do homem branco e o indígena, o sistema de concessão de terras por sesmarias. E na visão de Alexandre Rodrigues Ferreira a composição étnica da Capitania de São José do Rio Negro e o predomínio português na região. Ainda as estimativas populacionais no Grão-Pará. Mas outro elemento dentro do aspecto físico e social amazônico era o trabalho missionário que passa pela catequese até o aldeamento indígena. Já, na economia destacava-se o governo de Pombal que trouxe desenvolvimento a região. Ainda, a exploração das drogas do Sertão que no ponto de vista ecológico não contribuía com a natureza. A escravatura indígena durante quase dois séculos é 
reflexo da organização missionária na Amazônia. Os religiosos organizaram e dirigiram a sociedade colonial. Mas a importância indígena vai muito além, da mão-de-obra. Os hábitos e costumes indígenas estão presentes até hoje na região amazônica. A culinária amazônica é essencialmente indígena e os variados pratos são preparados com técnicas antigas. Outra questão é a miscigenação, o português e a índia criaram o novo tipo físico na região. Por último, o autor destaca quatro fatores essenciais na formação da vida social na Amazônia: o índio, o português, o Estado e o missionário.

\section{A ocupação e formação populacional da Amazônia}

A organização da sociedade colonial brasileira utilizou o sistema de divisão de terras em capitanias sob a forma de sesmarias (sistema que auxilia o Estado nas questões agrícolas e econômicas distribuía a terra destinada a produção). No entanto, na Amazônia tentaram implantar o mesmo sistema de cana-de-açúcar, mais pelas adversidades não teve o mesmo êxito do Nordeste. Mais se consolidou a coleta das especiarias que tiveram um ciclo econômico longo na região. Além do seu modo de vida diferenciado realizado pelos indígenas que foram persuadidos pelos portugueses e principalmente pela catequese dos missionários.

O processo social na Amazônia teve seu crescimento com as drogas do sertão no processo de democratização. Este que trouxe avanços nas questões geopolíticas, mais por outro lado dispersou o homem na natureza. Outro fator que fez parte desse processo foi a escravização indígena que estava presente em toda a vida colonial da Amazônia. Mas a economia estava voltada para o comércio das especiarias, como por exemplo: a canela muito apreciada na Europa. No entanto sofreu mudanças no sistema com o governador Mendonça Furtado que proibiu a escravatura indígena e travou um duelo com os jesuítas. Ainda estimulou a agricultura que ganhou força com a implantação da Companhia Geral de Comercio do Grão-Pará e a entrada dos negros na Amazônia.

A sociedade amazônica condicionada à natureza se mostrou sem vocação para institucionalizar num rígido patriarcalismo escravocrata, agrário e monocultor. A região se tornou mais ecológica e mais próxima aos elementos naturais, tendo a participação do nativo nas ações do Estado. Com a expulsão dos jesuítas, as atividades sociais e econômicas mudaram, houve a valorização da cultura regional condicionada pela natureza, isto é, o homem mais depende da floresta do que da agricultura.

\section{A economia na Amazônia}

A ocupação da região amazônica está ligada a sua gente, suas plantas e animais. Esta relação mostra a teia da vida e o conflito dos tipos humanos (colonizador e os indígenas) já que se desenvolvem conjuntamente. Mas, essa descrição é vista claramente pelas crônicas escritas principalmente por naturalistas que exaltam as belezas naturais da região. O texto apresenta o interesse dos nobres europeus pelos produtos da terra. Ainda destaca alguns produtos como o algodão, cacau, arroz, café e a cana-de-açúcar (esta no Pará na produção de aguardente) relatada nas crônicas de Spix e Martius. Além dos produtos existe o uso de plantas e ervas para curar doenças e mal-estares, como a 
catuaba que é tônico e estimulante e o jucá que serve para anemia, asma e reumatismo, entre outros. Para completar, o autor destaca os tipos de madeiras (cedro, ipê, pau-óleo entre outros) e os animais (o boi com a civilização do couro, as aves e em especial a tartaruga tanto para alimento como o uso da sua banha - para produzir a manteiga). Este tópico destaca o dinamismo cultural e social do homem amazônico e sua vida regional fundamental na ecologia social e humana da Amazônia.

\section{A formação da paisagem amazônica: seus personagens e produtos}

A ocupação da Amazônia estabeleceu personagens importantes para a formação social, como o colono, o homem que se dedica ao desbravamento e a humanização da terra. Ainda, possui uma pequena agricultura para sua subsistência e comércio local. Já o extrativista ou dono de sítio cultiva as plantas, mas nem por isso deixava de fazer a coleta das especiarias. Continua, com o fazendeiro (misto de extrativista com pequeno agricultor) e seus agregados, os agentes das atividades públicas (servidores públicos) todos de uma forma ou de outra utilizam os indígenas nas atividades econômicas e sociais. A mulher indígena teve o mesmo papel como em qualquer outra sociedade, fazia os serviços caseiros, cuidava das crianças e das atividades com o algodão. As primeiras especializações regionais começaram a aparecer como pescador, caçador, remador e outros. Diante disso, Arthur Reis (1989) classificou o homem amazônico como sertanistafluvial que abrangia de certa forma todos os citados. O autor ressalta a representação da canoa que continua na paisagem social da Amazônia que também lembra a figura do regatão, com habilidade comercial e exposição dos gêneros de consumos (alimentos). Assim, o autor retoma os cultivos de arroz, mandioca, milho entre outros que contribuíram para o fortalecimento da produção e do comércio da Amazônia. A utilização de técnicas para o arroz e da cana-de-açúcar estimularam o desenvolvimento na região. No caso da cana a expansão de engenhos. No entanto devido às más qualidades dos produtos e pela abertura de concorrência (novos mercados) muitos produtos derrocaram na economia mundial.

A Amazônia com sua vasta região trouxe preocupações ecológicas definidas nas utilidades geográficas, políticas e sociais. Com a independência outros povos puderam entrar no país, com suas culturas e seus costumes. Possibilitando o crescimento da região, lembrando que foram os ingleses que comandaram o Ciclo da Borracha.

\section{Segundo tempo e outros tempos: da borracha até uma outra Amazônia}

Se no primeiro tempo amazônico Leandro Tocantins trata do tempo histórico, tempo sócio-ecológico e tempo econômico, os quais estão definidos pelas drogas do sertão, o segundo tempo é revelado e consagrado pelo ciclo do ouro-negro, que também é uma droga do sertão, mais uma exclusiva droga do sertão: a borracha. O ciclo da Borracha foi um dos mais efêmeros ciclos econômicos do Brasil. Da humilde origem em 1870 o extrativismo da borracha ocupou em 1910 um quarto das exportações brasileiras (SOUZA, 2009). Trata-se da mais nova terra do planeta, ainda não totalmente desbravada pelo homem, terra cheia de paradoxos de sua natureza desnorteante, desafiando as leis 
da ciência e até mesmo às leis divinas. No entanto é verdade que o homem influi sobre o meio, domina-o, dirige-o: isto, porém quando quer, ou quando pode. Também é verdade que na Amazônia o homem tem influído negativamente sobre o meio, e nem sonhou de dominá-lo quanto mais de dirigi-lo (BASTISTA, 2003). Assim sendo, o segundo tempo amazônico, tem sua representatividade eleita por um produto natural da terra (não esquecendo que representações não espelham o mundo, elas o criam), que ganhou fama por espalhar um otimismo sem propósito e sinônimo de crescimento sem sustentação. A Hévea - que nasce alva como o leite e fica depois negra pelo contágio da ambição humana (BASTISTA, 2003).

\section{Borracha e o mundo amazônico}

Os índios Omágua, que chamavam de "heve" uma matéria flexível, fabricada pela coagulação do leite de uma árvore, não podiam imaginar o que aquela seiva rica iria causar a eles e ao mundo amazônico. E porque usavam o material para fazer seringas, os portugueses logo batizaram aquela árvore de seringueira (SOUZA, 2009). Na Amazônia eram os índios os donos e manipuladores de uma goma que extraiam de certas árvores da floresta. Faziam-lhes incisões no caule, e brotava um leite branco, meio pastoso, em miríadas de pontos, escorrendo, em fios de âmbar, pelo tronco, até cair sobre folhas vegetais estendidas no solo (TOCANTINS, 1982). Os índios foram considerados como uma “droga do sertão". Mas eles constituíam uma “droga” especial, porque eram os únicos capazes de produzir outras "drogas" (SILVA, 1996). Então várias notícias chegaram à Europa desse estranho leite vegetal e despertou o imaginário de muitos, fervilhando o imaginário, e todos queria ter a revelação de um novo objeto, com o pressentimento de que ela viesse a integrar-se, utilmente, na vida civilizada. Com a utilização de técnicas no aprimoramento das técnicas dos índios o europeu revolucionou o emprego do látex e assim sua consagração e o êxito comercial, que passo a passo verificou-se o crescimento dos índices de importação amazônica da borracha, para as variadíssimas utilizações.

Depois dos descobridores espanhóis, vieram os franceses, em 1743 a Academia de Paris enviou La Condamine e Fresneau, acompanhado de comitiva, para o estudo de uma pequena amostra de uma goma resinosa, cor de um escuro carregado, quase preto, e que disse chamar-se "caouthouc", designação por que, ainda hoje, é geralmente conhecida, no continente europeu. Reconta La Condamine ser a árvore do que provém chamada hevé, que, podemos acrescentar, tornou-se o nome específico do grupo, que produz as mais finas qualidades, conhecidas como borracha do Pará, ou a espécie de hévea (MENDES, 2004).

A região havia se integrado definitivamente na indústria extrativa do látex, e um novo capítulo da história do homem nos trópicos surgiu com a marca do épico, do sensacional. A borracha vinha transformar a sociedade amazônica, a começar pelo modo de ser individual. Dominou corpo e alma do homem, até ao sacrifício mais extremo, para oferecer à humanidade uma parcela de bens materiais (TOCANTINS, 1982). Portanto a borracha passou a ser uma droga do sertão, de terminologia colonial, que se destacou mediante um cunho imperial, sufocando todas as outras manifestações de vida econômica da região. 


\section{Simbiose: trinômio ecológico}

Jamais um trinômio ecológico: a seringa, o seringal e o seringueiro, interrelacionou-se de maneira tão íntima para produzir vida na sua profunda expressão humana, em que o bom se junta ao mau, nessa mescla imponderável de culturas que caracteriza a interação entre homem e planta-seringueira, como nas folhas no ramo de D'Annunzio, vistas pela cegueira social da época (TOCANTINS, 1982). Esse trecho da idéia de como existe interação, detalhadamente pode-se afirmar que Seringa, na linguagem amazônica, era uma bomba sem êmbolo, em forma de pera oca, feita de borracha, com orifício na extremidade, no qual se adaptava uma cânula. Invenção dos índios, que tinham o hábito singular de utilizá-la.

Chegando ao conhecimento dos portugueses tais objetos, saudados como úteis à civilização, o seu nome passou a ser, também, o da árvore que jorra o leite. Árvore de seringa. E da seringa surgiu o seringal, o espaço físico-social onde se erguem, dispersas pela floresta, as espécies vegetais da borracha. E do seringal, o seringueiro, o homem que se associa à planta, para explorá-la. Uma trilogia marcadamente ecológica. Mas não esquecendo o aparecimento do Seringalista - designado pelo proprietário do seringal, que antes, era o patrão ou, mesmo, seringueiro, confundindo-se, na nomenclatura, com o verdadeiro extrator da borracha. Assim, passou a ser um quarteto ecológico: seringa, seringal, seringalista e seringueiro. A borracha levou o homem a um grau de subordinação à floresta. Tudo transpira sociologicamente o suor da terra, da mata, dos rios, dos animais, suor que se impregna ecologicamente no corpo do homem, e passa, também, a ser o seu suor (TOCANTINS, 1982). Ainda no seringal, destaca-se a simbiose entre os tipos humanos nas figuras dos: Mateiros - grupo de homens que penetram na selva para descobrir seringueiras; Toqueiros - que ajudam os primeiros e abrem a "estrada" na floresta e os Comboieiros - que conduzem os burros de carga para o centro e trazem a borracha para a beira. Compreendemos que os tipos selecionados estão sedentarizados em suas paisagens originárias, constrangidos em sua mobilidade geográfica aos percursos de um gênero de vida particular. Além do território, base, solo comum em que se enraízam os homens e do qual brotam certos produtos que fazem a riqueza nacional, entrelaçam-se uma outra modalidade de aproximação entre os diferentes tipos humanos: as imagens destes tipos regionais expressam uma representação positiva dos brasileiros reconhecidos em diferentes formas de trabalho (TOCANTINS, 1982).

\section{Borracha: qual foi seu papel na Amazônia?}

Podemos compreender que uma civilização é um tipo de comunidade ou de sociedade humana que conseguiu um determinado nível da cultura, em contraste com comunidades primitivas que faltam essa cultura. Também utilizado para caracterizar uma sociedade ou um grupo de sociedade através de suas instituições, costumes, técnicas, crenças, etc. Assim a borracha criou a sua civilização, entre algumas glórias e muitas ambições (TOCANTINS, 1982).

O jesuíta Leonel Franca (1949) apud Tocantins (1982), afirma que "cada grupo social possui as suas técnicas, organiza e estrutura a sua família, regula, mediante normas 
estáveis, as relações de convivência, encarna em formas variadas a manifestação de seus sofrimentos estéticos, morais e religiosos". A todo esse conjunto de condições materiais e espirituais, ele intitula de civilização. E assim, pode-se tomar, no sentido geral, a civilização da borracha.

Percebe-se o diferencial da região amazônica, se destacando dos demais, pois em parte alguma da terra a civilização encontrará às suas ordens um tão formidável campo de experimentação econômica. Clima ótimo, com todas as variantes de salubridade; solo ubérrimo, pronto a desdobrar-se em colheitas magníficas; subsolo opulento de todos os metais e do petróleo. E, por sobre tudo isso, legiões de trabalhadores dispostos a fazer desta Planície Verde uma região feliz. Na Amazônia há lugar para todos (MENDONÇA, 1943). Por isso deu-se como civilização da borracha, a qual se tornou um produto universal e ubíquo a partir do começo do século XX. De tal forma está presente no mundo moderno, mas que as pessoas não se dão conta. Impedindo de que se pense que no início a borracha foi tida como uma matéria milagrosa, no começo do século XIX. Deixando como legado as cidade de Belém do Pará e Manaus que eram umas das cidades mais desenvolvidas do Brasil. Manaus foi à primeira cidade brasileira a ser urbanizada e a segunda a possuir energia elétrica. Ambas possuíam luz elétrica, água encanada, esgoto, amplas avenidas, por onde passavam bondes elétricos, além de construírem imponentes e luxuosos edifícios (Teatro da Paz, Mercado de Peixe, Mercado de Ferro, palacetes residenciais, em Belém do Pará; Teatro Amazonas, Palácio do Governo, Mercado Municipal, prédio da Alfândega, em Manaus), eram consideradas dentre as cidades mais prósperas do mundo (DEAN, 1989), “a esse respeito Leandro Tocantins, cita Belém e Manaus, ao alvorecer do século XX, já eram duas cidades dignas de figurar ao lado das melhores do Brasil, sem temer confrontos (1982, p. 89)", a fortuna de Manaus e Belém, [...] contabilizavam imensas somas de dinheiro que corriam livremente (SOUZA, 2009)

\section{O declínio da borracha e o cenário na Amazônia}

O cosmopolitismo do Ciclo da Borracha, face e sinal de uma triste alienação, parece algo forçado, produto de um salto brusco. A Amazônia, na historiografia esquemática que se escreve sobre ela, parece ter experimentado um vigor inesperado que a retirou do silencioso passado colonial, com suas vilas de poucas casas, para um ritmo trepidante e voraz, o comércio da borracha vinha proporcionar inquietudes inéditas (SOUZA, 2009).

O coronel da borracha, ambicioso, acreditava na exclusividade, o ouro pode surgir em qualquer terreno, não é privilégio de nenhuma área da terra, enquanto a borracha vem de um organismo vivo, que nasce e cresce, identificável entre as plantas da floresta espalhadas por Deus no território amazônico. A seringueira, ao contrário do filão de ouro, mostrava-se inesgotável, símbolo da vida, da bondade e da paz, essa riqueza parecia trazer marcas benéficas (SOUZA, 1994). A concorrência do Oriente surpreendeu a sociedade amazônica, vivendo em plena euforia de lucros, que possibilitaram as grandes obras públicas nos Estados do Pará e Amazonas. Na Amazônia o homem acostumado apenas a extrair da selva escolhendo as melhores árvores dispersas, aqui e acolá. Já no Oriente, aplicaram técnicas ao cultivo, juntamente com gigantescas plantações 
em linhas simétricas instruídas por novos processos de trabalho, o que resultou na diminuição de custos e possibilidades de competição. Por isso a borracha da Amazônia não conseguiu resistir. "As casas aviadoras suspenderam o crédito aos seringais. Os Seringais despovoaram-se, e seus proprietários, endividados com os aviadores, por sua vez não recebiam o produto dos seringueiros, e estes se desinteressavam de extraí-lo, por causa de seus preços ínfimos. No fim de tudo, desânimo e desolação entre as populações regionais" (TOCANTINS, 1982).

No entanto o organismo sócio-ecológico amazônico foi buscar, de novo, no arsenal da floresta, novas bases para sua vida econômica. Com sucesso na exportação de novos "produtos" e com a guerra e pós-guerra a Amazônia viveu um fenômeno de transição de uma economia orientada para a guerra, em marcha de adaptação ao período de paz. Data precisamente do pós-guerra, uma nova fase econômica para a região, a que se pretende, aqui, corresponder a uma "outra Amazônia", dentro e outros tempos. Juntamente com o descolamento de uma produção antes indicada para o mercado exterior e agora para a praça nacional. Depois do ciclo da borracha a face da Amazônia se transformou completamente. A economia do látex quebrou o isolamento e buscou integrar a região ao mercado internacional e nacional. Um dos principais fatores desta transformação foi à mudança do perfil populacional, provocado pelas inúmeras levas de imigrantes que chegaram atraídos pelas riquezas do látex e pela necessidade de mão de obra (SOUZA, 2009). Então a natureza aqui não mais entra em colaboração com a anátema de Buckle: - "De tão apavorantemente grande e fecunda, não deixa lugar para o homem” (MENDONÇA, 1943).

\section{Considerações finais}

Pensar em Amazônia remete ao imaginário do desconhecido, devido a imensidão, das terras ainda não revelada ao mundo, sua cultura ainda não desmitificada, se é possível tal fato, então esse fascínio a cerca da Amazônia representou a construção de uma Amazônia remetida ao nível do imaginário, através dos discursos intimamente vinculados desde a chegada do primeiro colonizador ao "Novo Mundo", criando-se a representação enaltecendo dois níveis: a representação de Amazônia no ponto de vista do exógeno, ou seja, estruturado pelos discursos externos, e no olhar do endógeno, esse sim elaborado pelos protagonistas que viveram na região.

Portanto quando Tocantins insere o tempo, nas articulações sócio-ecológica e espacial, ou seja, homem e terra, sua percepção indica um diferencial do homem amazônico, um indivíduo biológico, ao qual sua relação dentro de uma concepção brasileira existe uma dinâmica tríbia, que apoiado em Gilberto Freyre a cerca desse homem temporal diz que se apenas se procura viver no futuro, torna-se utópico, e se apenas se liga ao passado - torna-se arcaico, assim o homem amazônico vive imerso no tempo, ele é um ser - um estar sendo.

Assim a materialização da natureza é um elemento presente nos discursos externos sobre a região, é o que encontramos também na obra de Leandro Tocantins, nos quais denotam dicotomias como paraíso $\mathrm{x}$ inferno e civilização x barbárie. Não esquecendo que para o habitante da Amazônia não existe uma ou várias concepções, pois 
não há o distanciamento necessário para a construção de novos conceitos. Prevalece, neste caso, o reconhecimento e a identidade com o lugar, que são diretamente vivenciados.

\section{Referências}

BATISTA, Djalma. Amazônia - Cultura e Sociedade. Org. Tenório Telles. Manaus: Editora Valer, Governo do Estado do Amazonas, Editora da Universidade Federal do Amazonas, 2003.

BECKER, Bertha K. Amazônia: Geopolítica na virada do III milênio. Rio de Janeiro: Garamond, 2007.

CORRÊA, Roberto Lobato. Estudos sobre a rede urbana. Rio de Janeiro: Bertrand Brasil, 2006.

DEAN, Warren. A luta pela borracha no Brasil: um estudo de história ecológica. São Paulo: Nobel, 1989.

FREYRE, Gilberto. Além do apenas moderno. Rio de Janeiro, 1973.

GOMES, Paulo Cesar da Costa. Cenários para a Geografia: sobre a espacialidade das imagens e suas significações. In: ROSENDAHL, Zeny; CORREA, Roberto Lobato (org.). Espaço e Cultura: Pluralidade Temática. Rio de Janeiro: EDUERJ, 2008.p. 187-209.

LAGO, Antonio; PÁDUA, José Augusto. O que é Ecologia?. 8. Ed. (primeira edição, 1984). Editora Brasiliense, 1989.

MENDES, J. A., A crise Amazônica e a borracha. Manaus: Editora Valer e Governo do Estado do Amazonas, 2004

MENDONÇA, Carlos. Gente do Nordeste no Amazonas (Reportagem em torno do repovoamento do Amazonas em 1942). Manaus: Imprensa Pública, 1943.

REIS, Arthur Cezar Ferreira. História do Amazonas. 2 ed. Belo Horizonte; Itatiaia; Manaus: Superintendência Cultural do Amazonas, 1989.

SILVA, Marilene Corrêa da. O Paiz do Amazonas. Manaus: Editora da Universidade do Amazonas, 1996.

SPIX, Johann Baptist Von; MARTIUS, Carl Friedrich Philipp Von. Viagem pelo Brasil (1817-1820). Belo Horizonte: Ed. Itatiáia; São Paulo: EDUSP, 1981.

SOUZA, Márcio. Breve história da Amazônia. São Paulo: Marco Zero,1994.

, Márcio. História da Amazônia. Manaus: Editora Valer, 2009.

TOCANTINS, Leandro. O rio Comanda a Vida. Uma interpretação da Amazônia. Biblioteca do Exército editora: Rio de Janeiro, 1952.

, Leandro. Amazônia: natureza, homem e tempo. 2. Ed. Rio de Janeiro:

Biblioteca do Exército Editora, 1982. 
Márcio Silveira Nascimento

Mestrando em Geografia pela Universidade Federal de Roraima - UFRR.

Instituto de Geociências. Membro do Grupo de pesquisa Interdisciplinaridade, Comunicação \& Políticas Públicas do Núcleo de Pesquisa Semiótica da Amazônia (NUPS). Campus do Paricarana. Av. Cap. Ene Garcez, 2413 - Bairro Aeroporto, Cep: 69310-000.

E-mail: marciosn.geo@gmail.com

Jaqueline do Espírito Santo Soares dos Santos

Mestre em Geografia pela Universidade Federal do Amazonas - UFAM.

Membro do Núcleo de Estudos e Pesquisas das Cidades na Amazônia Brasileira (NEPECAB). Av. General Rodrigo Octávio Jordão Ramos, 3000, Campus

Universitário, Setor Norte - Coroado, Cep: 69077-000.

E-mail: jackey_santos@yahoo.com.br

Recebido para publicação em agosto de 2014 Aprovado para publicação em janeiro de 2015 